\title{
The Dramatic Reversal of Hashish-Induced Junctional Tachycardia and Unstable Angina with Standard Therapy in Heavy Smoker Patient
}

\author{
Yasser Mohammed Hassanain Elsayed* \\ Critical Care Unit, Fraskour Central Hospital, Damietta Health Affairs, Egyptian Ministry of Health \\ (MOH), Damietta, Egypt. \\ *Corresponding Author: Yasser Mohammed Hassanain Elsayed, Critical Care Unit, Fraskour \\ Central Hospital, Damietta Health Affairs, Egyptian Ministry of Health (MOH), Damietta, Egypt.
}

\begin{abstract}
Rationale: Smoking cannabis is known to be a rare acutely trigger acute coronary syndrome Cigarette smoking is a strong, independent risk factor for acute and chronic ischemic heart disease. Hashish smoking, unstable angina, and pass phenomenon are possible causes for junctional tachycardia.

Patient Concerns: A middle-aged married heavy smoker male patient presented in the emergency department with unstable angina within two hours post-two hashish cigarette.

Diagnosis: Hashish-induced junctional tachycardia and unstable angina was the most probable diagnosis. Interventions: Electrocardiography, Echocardiography, and non-baric-oxygenation.

Lessons: Hashish smoking can be inducing unstable angina and junctional tachycardia, especially in the heavy smoker one. The major predisposing factor in hashish-induced acute myocardial infarction was a heavy cigarette smoking. So, How are you dealing with a heavy cigarette smoker patient presented with unstable angina after hashish cigarette smoking?
\end{abstract}

Outcomes: Dramatic reversal of Hashish-induced junctional tachycardia and unstable angina with standard anti-ischemic therapy in heavy cigarette smoker.

Keywords: Hashish-induced junctional tachycardia and unstable angina, hashish, cannabis, junctional tachycardia, unstable angina, cigarette smoker

Abbreviations

AVN: Atrioventricular node, ECG: Electrocardiography, ICU: Intensive care unit, MI: Myocardial infarction, NSR: Normal sinus rhythm, O2: Oxygen, SAN: Sinoatrial node, THC: Tetrahydrocannabinol, VR: Ventricular rate

\section{INTRODUCTION}

Worldwide, cannabis is considered the most commonly utilized outlawed illegal substance ${ }^{1}$. Its enormous usage is highly consumed in young people (15- to 34-year-olds) ${ }^{1}$. However, the main source of cannabis is the Cannabis sativa plant $^{2}$. So, there are three major types of cannabis products: herb (marijuana), resin (hashish) and oil (hash oil) ${ }^{3}$. The most intense form of cannabis is cannabis oil, derived from the concentrated resin extract ${ }^{3}$. It may contain more than $60 \%$ of tetrahydrocannabinol (THC) content $^{3}$. Different classes of chemicals, including nitrogenous compounds, amino acids, hydrocarbons, sugar, terpenes, and simple fatty acids, together contribute to the unique pharmacological and toxicological properties of cannabis ${ }^{1}$. Delta-9-tetrahydrocannabinol ( $\Delta-9$ THC) and Cannabidiol [CBD), the two main ingredients of the cannabis Sativa plant, have distinct symptomatic effects ${ }^{1}$. As regards the United Nations Office on Drugs and Crime (UNODC), the amount of THC present in a cannabis sample is generally used as a measure of cannabis potency ${ }^{3}$. In humans, the acute effect of smoking cannabis usually manifests as an increase in heart rate with no significant change in blood pressure ${ }^{4}$. Of the negative effects of cannabis on the cardiovascular system including increased risk of acute coronary events, development of atrial ischemia, and increasing both heart rate and blood pressure ${ }^{5}$. Smoking cannabis is known to be a rare acutely trigger myocardial infarction $(\mathrm{MI})^{\mathbf{3}, \mathbf{6}}$. Cannabis 
has been linked to the dose-dependent way of inducing elevated rates of $\mathrm{MI}^{1}$. One large study of 1,913 adults conducted in the United States found both a significant association between MI and cannabis use and a dose-response effect ${ }^{5,6}$. Postulated mechanisms for this include complex interactions between increased oxygen $(\mathrm{O} 2)$ demand (due to increased heart rate and blood pressure), decreased $\mathrm{O} 2$ supply (due to an increase in carboxyhemoglobin) and coronary vasospasm ${ }^{2}$.

The involved nomenclature ${ }^{7}$ to understand the type of junctional rhythms (JR) is dependent on their rate. They are classified as follows: 1 . Junctional bradycardia: Ventricular rate $<40$ bpm. 2. Junction escape rhythm: Ventricular rate 40-60 bpm. 3. Accelerated junctional rhythm (AJR): Ventricular rate (VR) of 60-100 bpm. 4. Junctional tachycardia: Ventricular rate $>100 \mathrm{bpm}^{7}$. If there is a blockage for the sinoatrial node (SAN) electrical activity is blocked or is less than the automaticity of the atrioventricular node $(\mathrm{AVN}) / \mathrm{His}$ Bundle a JR starts. Numerous conditions and medications can lead to a diseased SAN and lead to the AVN/His Bundle to take over due to the higher automaticity of the ectopic pacemaker ${ }^{7,8}$. Junctional tachycardia may also be due to ischemia of the AVN, especially with acute inferior infarction involving the posterior descending artery, the origin of the AV nodal artery branch ${ }^{8}$. This rhythm may occur in persons of any age. Junctional rhythms, which are common in younger ${ }^{8}$. The following causes implicated in inducing junctional tachycardia ${ }^{7}$ : toxic and pharmacologic: e.g., cannabinoids, opioids, clonidine, reserpine, cimetidine, lithium, amitriptyline, radiation therapy, antiarrhythmics class I to IV (e.g., betablockers, calcium channel blockers, adenosine, and digoxin), ivabradine, and isoproterenol infusion, cardiovascular: e.g., acute and chronic coronary artery disease, rheumatic fever, repair of congenital heart disease, pericarditis, myocarditis, sick sinus syndrome, inherited channelopathy, endocrinal and metabolic: e.g., hypothyroidism, anorexia nervosa, sleep apnea, hypoxia, hyperkalemia, amyloidosis, and Lyme disease, central: e.g., neuromuscular disorder, $\mathrm{x}$-linked muscular dystrophy, intracranial hypertension, autonomic: vasovagal simulation (endotracheal suctioning), carotid sinus hypersensitivity, and traumatic: e.g., recent cardiac surgery and chest trauma ${ }^{7,8}$. Junctional tachycardia may also be due to the onset of acute coronary syndrome? Prognosis is good ${ }^{8}$. Complications of junctional rhythm are usually limited to symptoms such as dizziness, dyspnea, or presyncope ${ }^{8}$.

Cigarette smoking is a strong, independent risk factor for acute and chronic ischemic heart disease ${ }^{\mathbf{1 0}}$. Cigarette smoking is an important determinant of acute coronary events ${ }^{11}$. The importance of cigarette smoking is confirmed as a cause of acute coronary syndrome ${ }^{\mathbf{1 2}}$. The pathogenesis for the adverse effect of cigarette smoking on the coronary arterial circulation is complex and multi-factorial. Smoking increases both heart rate and blood pressure, thereby augmenting myocardial $\mathrm{O} 2$ demand. Thereafter, smoking reduces the dimension of the coronary arteries and coronary blood flow ${ }^{10}$.

\section{Case Presentation}

A 43-year-old married, driver, Egyptian male patient presented in the emergency department with acute severe chest pain and palpitation. The chest pain was anginal. Profuse sweating was the associated symptoms. The patient gave a recent history of smoking two hashish cigarettes. He was a heavy cigarette smoker (4060 cigarette per day for 17 years) The patient denied the history of cardiovascular diseases, smoking, drugs or special habits or the same attack. Upon physical examination; generally, the patient was tachycardic, sweaty, and anxious, with a regular heart rate of $110 \mathrm{bpm}$, blood pressure of $140 / 80 \mathrm{mmHg}$, respiratory rate of $16 \mathrm{bpm}$, the temperature of $36.4{ }^{\circ} \mathrm{C}$, pulse oximeter of $\mathrm{O} 2$ saturation; $97 \%$ and tachycardia on heart auscultation. No more relevant clinical data were noted during the clinical examination. He was admitted to the ICU as unstable angina. Urgent ECG was done showing junctional tachycardia (Figure 1A). The second ECG tracing was taken within 3 minutes of the first one. The junctional tachycardia was rapidly replaced with sinus tachycardia with the appearance of straight STsegment depressions in V4-6 leads (Figure 1B). The patient was initially managed in the ICU with $100 \% \mathrm{O}_{2}$ inhalation using nasal cannula at the rate of $5 \mathrm{~L} / \mathrm{min}$. Aspirin; four oral tablet (75 $\mathrm{mg}$ ), clopidogrel; four oral tablet $(75 \mathrm{mg}$ ), bisoprolol; one oral tablet (5 mg), enoxaparin; twice SC daily $(60 \mathrm{mg})$, and atorvastatin; one oral night tablet $(40 \mathrm{mg})$ were urgently given. Pethidine HCL (100 mg) was given for chest pain in intermittent doses as needed. The third ECG tracing was taken within 75 minutes of the 
The Dramatic Reversal of Hashish-Induced Junctional Tachycardia and Unstable Angina with Standard Therapy in Heavy Smoker Patient

first ECG tracing showing normalization of above ST-segment depressions and retune to normal sinus rhythm (NSR) (Figure 2). Clinical improvement with the disappearance of chest pain had happened. The only measured random blood sugar was $121 \mathrm{mg} / \mathrm{dl}$. The troponin test was positive ( $87 \mathrm{ng} / \mathrm{L})$. Later echocardiography was mild anterolateral hypokinesia with EF $55 \%$. No more workup was done. The case was initially managed as unstable angina. Hashishinduced junctional tachycardia and unstable angina was the most probable diagnosis. The patient was continued; aspirin tablet $(75 \mathrm{mg}$, once daily), clopidogrel tablet (75 $\mathrm{mg}$, once daily), nitroglycerin retard capsule $(2.5 \mathrm{mg}$ twice daily), enoxaparin; (60 $\mathrm{mg}$ twice SC daily), and atorvastatin; (40 mg one oral night tablet) until discharged. The patient discharged within 36 hours after controlling the chest pain, tachycardia, and serial electrocardiographic normalization with recommended outpatient clinic follow up.

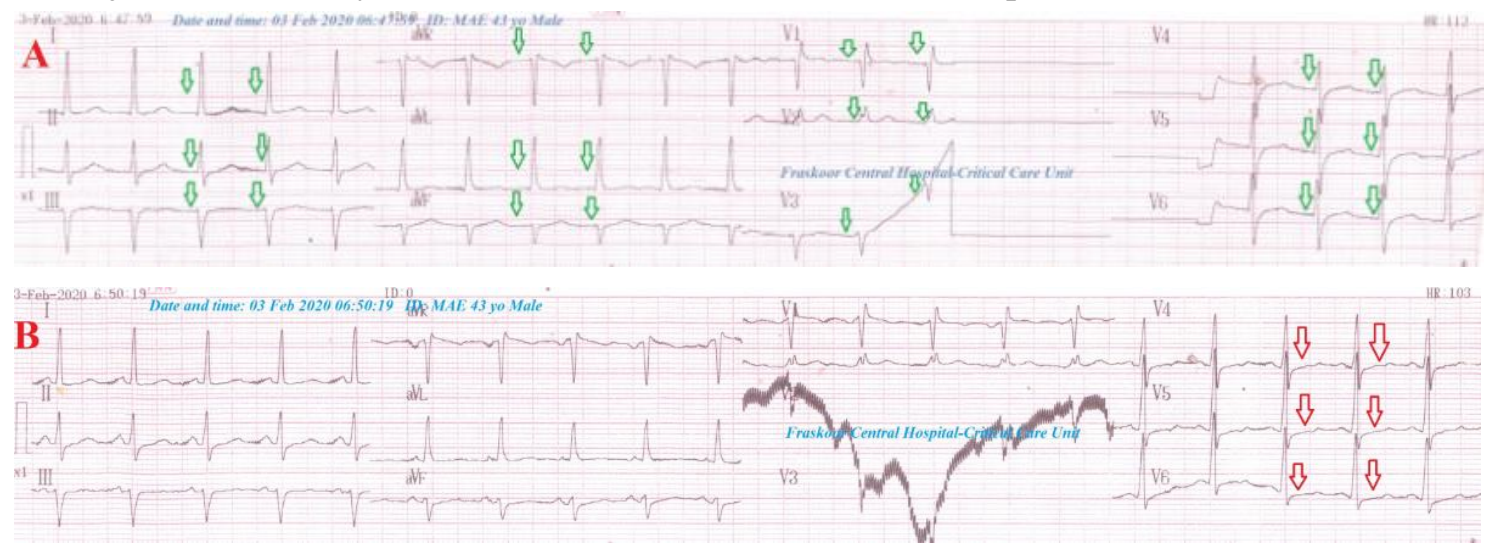

Figure1. Urgent ECG tracing was taken in the ICU showing evidence of junctional tachycardia with rapid regular VR, and absent "P-wave" (green arrows) (tracing 1A). Sinus tachycardia (VR; 100) with straight STsegment depressions in V4-6 leads (red arrows) have rapidly appeared (tracing $1 B$ ). There are incomplete right bundle branch block and artifact in lead V3.

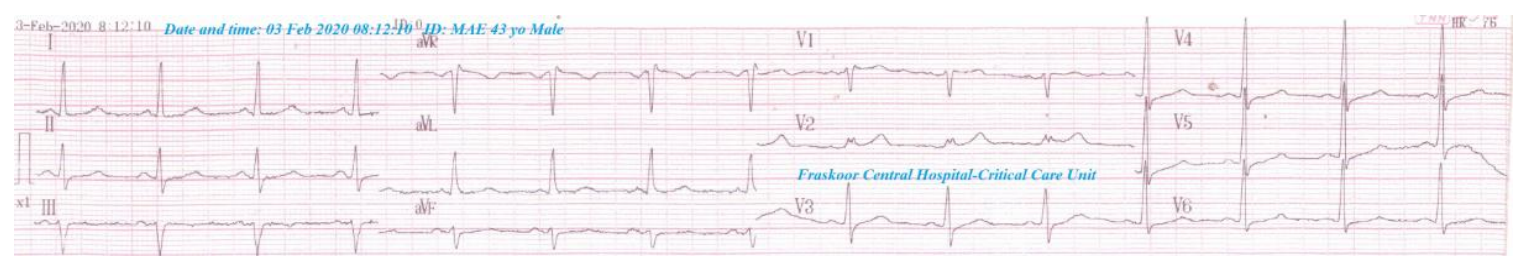

Figure2. ECG tracing was taken within 75 minutes of the first ECG tracing showing normalization of above STsegment depressions and retune to normal sinus rhythm (NSR with VR; 74)

\section{DISCUSSION}

- Overview; A middle-aged married heavy cigarette smoker male patient presented in the emergency department with unstable angina within two hours post-two hashish cigarette.

- The primary objective for the current case was the presence of unstable angina in the heavy smoker male patient within two hours post-two hashish cigarette.

- The secondary objective for the case study was; How are you dealing with a heavy cigarette smoker patient presented with unstable angina after two hashish cigarette smoking?

- Limitations of the study; there were no known limitations for the case study.
- I can't compare the study case with another one due to there was no publicized similar cases.

- Cession of cigarette smoking was strongly advised. Future planning for coronary angiography was recommended.

\section{CONCLUSIONS}

- Hashish smoking can be inducng unstable angina and junctional tachycardia, especially in the heavy cigarette smoker patient.

- The major predisposing factor in hashishinduced acute myocardial infarction was a heavy cigarette smoking.

- Unstable angina and pass phenomenon are possible other mechanisms for junctional tachycardia. 
The Dramatic Reversal of Hashish-Induced Junctional Tachycardia and Unstable Angina with Standard Therapy in Heavy Smoker Patient

- Thrombotic, coronary vasospasm, and hypoxia were suggested mechanisms for unstable angina.

\section{ACKNOWLEDGMENT}

I wish to thank the critical care unit nurses who make extra-ECG copies for helping me.

\section{REFERENCES}

[1] Karila L, Roux P, Rolland B, Benyamina A, Reynaud M, Aubin HJ, Lançon C. Acute and Long-Term Effects of Cannabis Use: A Review. Current Pharmaceutical Design. 2014;20 (25):4112 -8. DOI: 10.2174/138 161 28113199990620

[2] Don M, Gunawardena MV, Rajapakse S, Herath J, Amarasena N. Myocardial infarction following cannabis induced coronary vasospasm, case report. BMJ Case Rep. 2014;12. DOI:10.1136/bcr-2014-207020

[3] United Nations Office on Drugs and Crime (UNODC). Why Does Cannabis Potency Matter? Available online: http://www.unodc. org/unodc/en/frontpage/2009/June/ why-doescannabis-potency-matter.html (accessed $25 \mathrm{Jul}$ 2014).

[4] Pacher P, Bátkai S, Kunos G. Cardiovascular pharmacology of cannabinoids. Handb Exp Pharmacol. 2005;(168):599-625. PMID: 16596789 PMCID:PMC2228270 DOI:10.1007 13-540-26573-2_20

[5] Goyal H, Awad HH, Ghali JK. Role of cannabis in cardiovascular disorders. $J$ Thorac Dis. 2017 Jul;9(7):2079-2092. PMID:28840009
PMCID:PMC5542986 DOI:10.21037/jtd.2017. 06. 104

[6] REECE AS. Chronic toxicology of cannabis. Clinical Toricology. 2009;47:517-524. DO1:10. 1080115563650903074507

[7] Hafeez $\mathbf{Y}$ and Grossman SA. Junctional rhythm. Bookshelf ID: NBK507715 PMID: 29939537 StatPearls Publishing LLC.

[8] Available online from: https://www. ncbi. nlm. nih.gov/books/NBK507715/ (Accessed: May 14, 2019).

[9] Beinart SC. Junctional Rhythm. Available from: https://emedicine.medscape.com/ article/ 155146-overview (Accessed: Nov 27, 2018).

[10] Barbara A. ECGs Made Easy. $5^{\text {th }}$ ed. Elsevier. 2013 p. 160. ISBN 9780323170574

[11] Alemu R, Eileen E, Fuller, Harper JF, Feldman M. Influence of Smoking on the Location of Acute Myocardial Infarctions. ISRN Cardiology.2011;174358:1-3. doi:10. $5402 / 2011 / 174358$

[12] Quek DK, Lim LY, Ong SB. Cigarette smoking and the risk of myocardial infarction, and acute non-infarct coronary events among Malaysian women. Med J Malaysia. 1989 Sep;44(3):210-23. PMID: 2626136

[13] Negri E, La Vecchia C, Nobili A, D'Avanzo B, Bechi S. Cigarette smoking and acute myocardial infarction. A case-control study from the GISSI-2 trial. GISSI-EFRIM Investigators. Gruppo Italiano per lo Studio della Sopravvivenza nell'Infarto-Epidemiol ogia dei Fattori di Rischio dell'infarto Miocardioco. Eur J Epidemiol. 1994 Aug; 10(4):361-6. PMID: 7843337

Citation: Yasser Mohammed Hassanain Elsayed, "The Dramatic Reversal of Hashish-Induced Junctional Tachycardia and Unstable Angina with Standard Therapy in Heavy Smoker Patient", International Journal of Research Studies in Medical and Health Sciences. 2020; 5(3): 16-19.

Copyright: (c) 2020 Yasser Mohammed Hassanain Elsayed, This is an open-access article distributed under the terms of the Creative Commons Attribution License, which permits unrestricted use, distribution, and reproduction in any medium, provided the original author and source are credited. 